\title{
Dietitians' Requirements and Self-evaluation of Knowledge and Attitude for Educational Program Development of Sustainability Management at School Foodservice
}

\author{
$\mathrm{Na}$ Young Yi \\ Daejeon University, DaeJeon, Republic of Korea \\ nayoungl@dju.kr
}

\begin{abstract}
The purposes of the study were to identify dietitians' requirements and self-evaluation of knowledge and attitude levels for sustainability management at school foodservice and compare the knowledge and attitude by general characteristics. Excluding responses with missing data, 187 responses were used for data analysis. The respondents were $38.5 \%$ in their 30 s, $47.1 \%$ with 6 to 10 years of experience and $39.6 \%$ in elementary schools. In terms of knowledge, 'facility and energy management (4.24)' category received the highest perceived need score, followed by 'procurement (4.07)' and 'waste management (4.04)'. The knowledge category that received the highest self evaluation was 'procurement (3.59)', while the category that received the lowest self-evaluation was 'nutrition education (3.04)'. In terms of attitude, the highest perceived need was associated with 'procurement (4.21)', followed by 'facility and energy management (4.14)' and 'waste management (4.08)'. The attitude category that received the highest self evaluation was 'facility and energy management (3.88)', while the category that received the lowest self-evaluation was 'nutrition education (3.15)'. The dietitians' requirements of knowledge and attitude scores were significantly higher than their self-evaluated knowledge and attitude scores in all job functional areas $(p<0.001)$. In most areas, the needs and self-evaluation showed significant differences according to career, type of contract, and working school level. In all functional area, dietitians' knowledge and attitude scores of elementary school were the highest $(p<0.001)$.
\end{abstract}

Keywords: Sustainability, Management, School, Foodservice, Dietitian, Knowledge, Attitude

\section{Introduction}

Our society is currently facing a serious crisis due to environmental issues such as fine dust, climate change, and water shortage. These issues are not limited to mere environmental pollution problems, but are becoming social problems and causing significant social and economic costs, as well [1]. As social values become increasingly important, the neglect of addressing environmental pollution and social problems can lower the societal reputation of a company, which in turn can decrease long-term competitiveness [2][3][4]. Therefore, corporate social responsibility has become a survival strategy under the new management

Article history:

Received (February 14, 2018), Review Result (March 19, 2018), Accepted (April 30, 2018) 
environment where companies are pursuing sustainability management that considers environmental soundness and social responsibility in a comprehensive manner.

In the foodservice industry, various efforts are being made to implement sustainability management as well. For example, in the United States, the Green Seal and the Green Restaurant Association have provided the evaluation criteria for sustainability management with regards to restaurants [5][6]. However, in the case of school meals, while studies on ecofriendly ingredients, as well as the recognition of and the satisfaction among dietitians have been performed [7][8][9][10], research on sustainability management based on job categories of dietitians has rarely been conducted [4][11]. Therefore, the purpose of this study is to compare the requirements and self-evaluation of school-based dietitians' knowledge and attitude for sustainability management and to utilize the results as basic data for the development of an educational program regarding sustainability management.

\section{Methodology}

\subsection{Sample and data collection}

The questionnaires were administered to Korean dietitians for the requirement and selfevaluation of knowledge and attitude for sustainability management. The survey was conducted via email and direct visits from June 1 to June 30, 2016. A total of 220 copies were distributed and 195 copies were retrieved (recovery rate: $88.6 \%$ ). Of these, 187 copies were used for data analysis, excluding incomplete questionnaires.

\subsection{Survey}

The knowledge and attitudes required by dietitians for sustainability management were developed by referring to existing literature [5][6][12][13][14]. The task areas categorizing knowledge and attitudes of dietitians were menu management, procurement, food production, facility and energy management, waste management, nutrition education and personnel management. The knowledge and attitude requirements and the self-evaluation items were examined on a 5-point scale (1-point: not at all, 5-points: very much).

\subsection{Data analysis}

The collected data were analyzed using SPSS 24.0. Mean and standard deviation were performed for requirements and self-evaluation regarding knowledge and attitude. Cronbach's alpha coefficients on knowledge and attitude items were calculated for each task to ensure internal consistency. A paired t-test was conducted to identify the difference between selfevaluation and the requirements for knowledge and attitudes of dietitians by task.

\section{Results}

\subsection{Profile of respondents}

All respondents were female, 36.4\% (68 individuals) were in their 20s, 38.5\% (72 individuals) were in their $30 \mathrm{~s}$, and $18.7 \%$ (35 individuals) were in their 40s Table 1. Among which, $72.2 \%$ (135 individuals) graduated from a 4-year university program, 47.1\% (88 individuals) had worked in a company for 6-10 years, and 59.4\% (111 individuals) held permanent positions. Furthermore, 39.6\% (74 individuals) were in elementary school, $33.7 \%$ 
(63 individuals) in middle school, 26.7\% (50 individuals) in high school, and 79.1\% (148 individuals) worked in the city.

\subsection{Requirements and self-evaluation of dietitian' knowledge for sustainability management}

Cronbach's alpha was calculated as 0.65 to 0.83 for the evaluation of the dietitians' knowledge in the seven task areas, and internal consistency was secured Table 1. As a result of examining the degree of knowledge required to practice sustainability management, it showed a distribution of 3.47 to 4.66 points. The knowledge requirement score for each task was in the order of facility and energy management (4.23), procurement (4.07), waste management (4.04), food production (3.98), menu management (3.96), personnel management (3.48), and nutrition education (3.36). Self-evaluation of knowledge for practicing sustainability management showed a distribution of 2.71 to 3.96 points, and thus, all items were surveyed less than 4 points. Knowledge self-assessment scores by task were in the order of procurement (3.59), facility and energy management (3.48), waste management (3.36), food production (3.34), personnel management (3.29), menu management (3.25), and nutrition education (3.04). The results of comparing the dietitians' requirement of knowledge and self-evaluation by task indicated that requirement scores were significantly higher than the scores of self-evaluation in all 25 items $(\mathrm{p}<0.001)$.

Table 1. Requirements and self-evaluation of dietitian' knowledge for sustainability management

\begin{tabular}{|c|c|c|c|c|}
\hline & Knowledge statement & Requirement & $\begin{array}{c}\text { Self } \\
\text {-evaluation } \\
\end{array}$ & $\mathrm{t}$-value \\
\hline \multirow{5}{*}{$\begin{array}{c}\text { Menu } \\
\text { management } \\
(0.70)\end{array}$} & Knows principles for healthy menu planning ${ }^{1)}$ & $4.15^{2)} \pm 0.61$ & $3.39 \pm 0.62$ & $72.767^{2.8 *}$ \\
\hline & Knows menus that use eco-friendly (organic, pesticide-free, no antibiotics) ingredients. & $4.14 \pm 0.50$ & $3.43 \pm 0.50$ & $111.220^{*+*}$ \\
\hline & Knows development processes of standardized recipes. & $3.53 \pm 0.62$ & $2.71 \pm 0.62$ & $327.534^{* * *}$ \\
\hline & $\begin{array}{l}\text { Knows about the important relationship between activities for sustainability management and } \\
\text { students' long-term health. }\end{array}$ & $4.00 \pm 0.56$ & $3.46 \pm 0.74$ & $76.207^{* 2 * *}$ \\
\hline & Mean & $3.96 \pm 0.50$ & $3.25 \pm 0.45$ & $208.377^{*+1}$ \\
\hline \multirow{4}{*}{$\begin{array}{l}\text { Procurement } \\
\quad(0.68)\end{array}$} & Knows eco-friendly certification standards and labeling systems. & $4.66 \pm 0.47$ & $3.96 \pm 0.50$ & $66.829^{2 * 2 *}$ \\
\hline & Knows proper order procedures for standardized recipes. & $3.87 \pm 0.62$ & $3.31 \pm 0.61$ & $86.411^{28 *}$ \\
\hline & Knows purchasing procedures and storage principles that prevent food loss. & $3.94 \pm 0.78$ & $3.50 \pm 0.77$ & $62.607^{2 * * *}$ \\
\hline & Mean & $4.07 \pm 0.49$ & $3.59 \pm 0.52$ & $115.688^{* *+*}$ \\
\hline \multirow{6}{*}{$\begin{array}{l}\text { Food production } \\
\quad(0.83)\end{array}$} & Knows procedures for production management of standardized recipes. & $3.73 \pm 0.57$ & $3.11 \pm 0.57$ & $96.668^{* 2 *}$ \\
\hline & Knows energy conservation methods in pre-processing and cooking processes. & $4.28 \pm 0.68$ & $3.72 \pm 0.68$ & $59.997^{* 3 *}$ \\
\hline & Knows water saving methods in pre-processing and cooking processes. & $3.91 \pm 0.68$ & $3.48 \pm 0.68$ & $102.211^{*+*}$ \\
\hline & $\begin{array}{l}\text { Knows proper handling procedures of ingredients, including the disposal of discarded portions, } \\
\text { and the washing of pre-processed ingredients. }\end{array}$ & $3.83 \pm 0.78$ & $3.36 \pm 0.78$ & $62.726^{* 2 *}$ \\
\hline & $\begin{array}{l}\text { Knows proper computation methods for total production amounts, and production methods of } \\
\text { menu offered. }\end{array}$ & $4.10 \pm 0.76$ & $3.05 \pm 0.69$ & $293.915^{*+*}$ \\
\hline & Mean & $3.98 \pm 0.52$ & $3.34 \pm 0.67$ & $180.635^{*+*}$ \\
\hline \multirow{5}{*}{$\begin{array}{l}\text { Facility and energy } \\
\text { management } \\
(0.81)\end{array}$} & Knows energy (electricity, gas, etc.) conservation methods. & $4.32 \pm 0.58$ & $3.50 \pm 0.58$ & $129.278^{* *+*}$ \\
\hline & Knows water saving methods. & $4.22 \pm 0.67$ & $3.49 \pm 0.67$ & $147.140^{*+*}$ \\
\hline & $\begin{array}{l}\text { Knows procurement methods for energy-efficient equipment and appliances (refrigerator, heating } \\
\text { cabinet, lights). }\end{array}$ & $4.14 \pm 0.62$ & $3.38 \pm 0.61$ & $95.738^{s=*}$ \\
\hline & Knows standard routine inspection and repair methods of kitchen appliances. & $4.24 \pm 0.71$ & $3.55 \pm 0.71$ & $152.957^{*+*}$ \\
\hline & Mean & $4.23 \pm 0.58$ & $3.48 \pm 0.63$ & $236.326^{* *+4}$ \\
\hline \multirow{4}{*}{$\begin{array}{l}\text { Waste management } \\
\qquad(0.65)\end{array}$} & Knows methods of recycling food waste. & $3.74 \pm 0.58$ & $3.06 \pm 0.58$ & $134.143^{* *+*}$ \\
\hline & Knows methods of minimizing waste. & $4.21 \pm 0.76$ & $3.59 \pm 0.76$ & $83.069^{328}$ \\
\hline & Knows methods of minimizing food waste. & $4.18 \pm 0.60$ & $3.44 \pm 0.57$ & $85.416^{8 * *}$ \\
\hline & Mean & $4.04 \pm 0.53$ & $3.36 \pm 0.49$ & $159.426^{* *+1}$ \\
\hline \multirow{4}{*}{$\begin{array}{l}\text { Nutrition } \\
\text { education } \\
(0.69)\end{array}$} & Knows how to educate students on sustainability management. & $3.97 \pm 0.84$ & $3.22 \pm 0.84$ & $203.611^{*+*}$ \\
\hline & Knows how to use meal services for education for sustainability management & $3.47 \pm 0.80$ & $2.80 \pm 0.63$ & $125.015^{*+1+}$ \\
\hline & Knows how to guide students on reducing leftover food. & $3.94 \pm 0.57$ & $3.11 \pm 0.57$ & $293.928^{* *+1}$ \\
\hline & Mean & $3.79 \pm 0.54$ & $3.04 \pm 0.54$ & $351.782^{* *+*}$ \\
\hline \multirow{4}{*}{$\begin{array}{l}\text { Personnel } \\
\text { management } \\
(0.66)\end{array}$} & Knows how to educate cooks on sustainability management. & $3.83 \pm 0.74$ & $3.28 \pm 0.75$ & $59.713^{s * *}$ \\
\hline & Knows how to educate cooks on conservation of energy and water. & $3.88 \pm 0.84$ & $3.37 \pm 0.56$ & $72.745^{838}$ \\
\hline & Knows how to educate cooks on minimizing waste. & $3.77 \pm 0.67$ & $3.23 \pm 0.81$ & $52.036^{38 *}$ \\
\hline & Mean & $3.83 \pm 0.54$ & $3.29 \pm 0.51$ & $97.814^{s .2 *}$ \\
\hline
\end{tabular}

1) A 5-point Likert-type scale was used (1: strongly disagree $\sim$ 5: strongly agree), 2) Mean $\pm S D$, ***p<0.001 
Table 2. Requirements and self-evaluation of dietitian' attitude for sustainability management

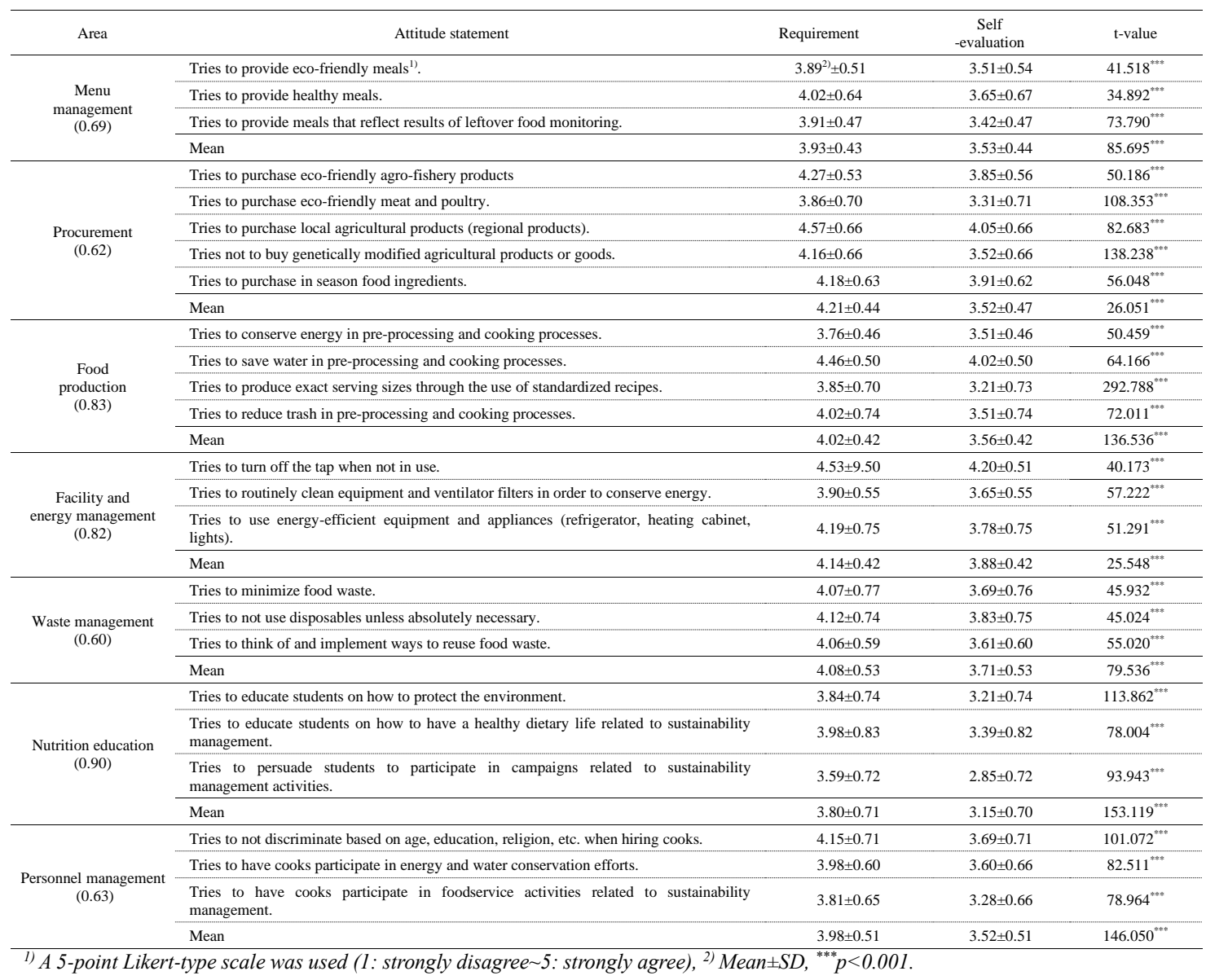

\subsection{Requirements and self-evaluation of dietitian' attitude for sustainability management}

Cronbach's alpha was calculated to be 0.62 to 0.90 for the evaluation of dietitians' attitude in the seven task areas, and the internal consistency was secured Table 3. The survey on attitudes required by the dietitians to practice sustainability management showed a distribution of 3.53 to 4.57 points. Meanwhile, the self-evaluation of the dietitians regarding attitudes for sustainability management showed a distribution of 2.85 to 4.20 points. The scores of the attitude of each attitude by task was in the order of procurement (4.21), facility and energy management (4.14), waste management (4.08), food production (4.02), personnel management (3.98), menu management (3.93), and nutrition education (3.80). The scores of the self-evaluation on the attitude towards tasks were in the order of facility and energy management (3.88), waste management (3.71), food production (3.56), menu management (3.53), procurement (3.52), personnel management (3.52), and nutrition education (3.15). The result of comparing the dietitians' requirement regarding attitudes and self-evaluation by task indicated that requirement scores were significantly higher than the scores of self-evaluation in all 25 items ( $\mathrm{p}<0.001)$. The results of requirements and self-evaluation regarding attitudes by task indicated that the requirements of all 25 items were significantly higher than those of their self-evaluation $(\mathrm{p}<0.001)$. 


\section{Conclusions}

To effectively implement sustainability management in school meals, knowledge of sustainability management should be provided for each task of the dietitian, and a high level of attitude within the dietitians is an essential factor. The results of this study indicate that the self-evaluation scores of dietitians were low in all items, and thus, training and education programs should be developed to improve the knowledge and attitude of dietitians regarding sustainability management. To encourage active participation of dietitians, it is necessary to provide systematic support and education to ensure that they have a solid attitude and provide knowledge about proper sustainability management.

\section{Acknowledgement}

This research was supported by the Daejeon University Research Grants (2015).

\section{References}

[1] Korea Environment Corporation, Think Green, 2014 Report of Sustainability Management, (2014).

[2] M.E. Porter and C. Van der Linde, "Green and competitive: ending the stalemate," Harvard Business Review, vol.73, no.5, pp.20-134, (1995)

[3] Korea Business Council for Sustainable Development, Sustainability management framework and practical tasks. KBCSD, Seoul, Korea, (2004)

[4] N.Y. Yi, "Development of the contents of the guideline for dietitians' Knowledge, Attitudes and Practices(KAP) for sustainable management at school foodservice," Journal of Korean Society Food Culture, vol.32, no.6, pp.513-526, (2017)

[5] Green Seal, "A certification guidebook for GS-55," Green Seal's Environmental Standard for Restaurants And Food Services, Available from: http://www.greenseal.org/Portals/0/Documents/Standards/GS-55/GS55\%20Guidebook\%202015.pdf, (2014)

[6] Green Restaurant Association, Certification Standards of 2014, Available from: http://docs.wixstatic.com/ugd/4d780f_08444a312ee14cafab5c580f941d961f.pdf, (2014).

[7] J.O. Rho and M.O. Kim, "A study on the utilization, recognition, and satisfaction of environment-friendly agricultural products in school food services according to the type of food service in Jeonbuk area," Korean Journal of Human Ecology, vol.20, no.2, pp.427-437, (2011)

[8] S.H. Jung, Y.E. Lee, and E.H. Park, "Use and perception of environmentally-friendly ingredients by dietitians in Chungbuk," Journal of the Korean Society of Food Science and Nutrition, vol.44, no.10, pp.1567-1582, (2015) DOI: 10.3746/jkfn.2015.44.10.1567

[9] S.C. Ahn and S.H. "The influence of sustainable management at institutional foodservice on store image and behavioral intention," Journal of Nutrition and Health, vol.48, no.2, pp.199-210, (2015)

[10] N.Y. Yi and K.E .Lee, "Requirements and self-evaluation of knowledge and skills, necessary for effective nutrition teachers perceived by school foodservice dietitians," Korean Journal of community Nutrition, vol.4, no.2, pp.90-205, (2009)

[11] N.Y. Yi, "Dietitians' self-evaluation and barriers to sustainable practices for school foodservice management - Focused on daejeon and chungnam area," Korean Journal of Food Cookery Society, vol.33, no.1, pp.342352, (2017)

[12] S.C. Ahn, "A study on the perception of environment-friendly agricultural products among dietitians in the capital area," Korean J Culin Res, vol.20, no.4, pp.144-156, (2014)

[13] H.J. Chang, D.B. Jeong, and S.M. Anna, "Criteria for sustainable practices of restaurant: Suggestion through review of related certification system at home and abroad," Korean Journal of Foodservice Management Society, vol.9, no.1, pp.347-365, (2016) 
Dietitians' Requirements and Self-evaluation of Knowledge and Attitude for Educational Program Development of Sustainability Management at School Foodservice

[14] J.Y. Yoo, "The study of measure for sustainability and necessity of environment-friendly qualification standard of restaurants," International Journal of Tourism, Hospitality Research, vol.29, no.5, pp.173-185, (2015) 